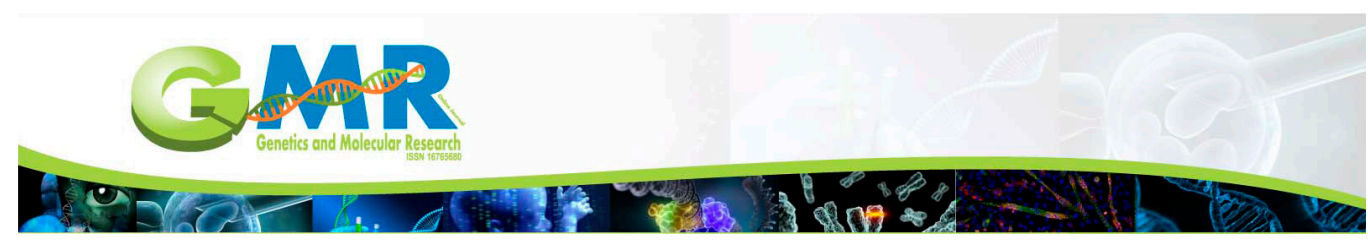

Thesis Abstract

\title{
Fermented milk elaborated with Camellia sinensis
}

\author{
O.A.S. Ribeiro, M.I.A. Silva and C.A. Boari \\ 2013. Universidade Federal dos Vales do Jequitinhonha e Mucuri, Campus JK, \\ Diamantina, MG, Brasil \\ Master's thesis. Orienting Prof.: C.A. Boari \\ Corresponding author: O.A.S. Ribeiro \\ E-mail: oribeiroea@gmail.com \\ Genet. Mol. Res. 15 (2): gmr. 15028686 \\ Received April 1, 2016 \\ Accepted April 1, 2016 \\ Published May 13, 2016 \\ DOI http://dx.doi.org/10.4238/gmr.15028686
}

This study aimed to develop and to characterize fermented dairy beverage formulated with Camellia sinensis. The infusion was elaborated with the addiction of dehydrated leaves of $C$. sinensis in whey $(1 \mathrm{~g} / 100 \mathrm{~g})$ which added in sweetened milk $(10 \%$ sucrose w/w) coagulated by Streptococcus salivarius subspecies thermophilus and Lactobacillus delbrueckii subspecies bulgaricus in proportions of 10, 20, 30 and $40 \%(\mathrm{v} / \mathrm{w})$. The control treatment consisted of yogurt added with sucrose $(10 \% \mathrm{w} / \mathrm{w})$. Analysis were performed to quantify dry mass, moisture, ash, protein, fat, sodium, acidity, total quantification of lactic acid bacteria, total antioxidant activity and viscosity at the initial time of production and at 15 and 30 days of storage. Chromatographic determination of volatile compounds and sensory tests of acceptance and consumption intention were conducted at the initial time of production. Dry matter content, moisture, ash and total count of lactic acid bacteria from fermented milk drink formulations were not significantly affected by the amount of infusion of $C$. sinensis. However, the content of protein, fat and sodium were significantly lower with the increase of the proportion of infusion incorporated into the product. Significant reduction in apparent viscosity occurs with the increase in the amount of infusion added. The total antioxidant 
activity of the formulations was significantly higher as higher were the amount of added infusion. The addition of infusion contributed to the diversification of volatile aroma and taste makers in the product. The formulation of fermented dairy drink with addition of $30 \%$ infusion C. sinensis was better evaluated in sensory tests, with greater acceptance and greater consumer intent of consumption.

Key words: Antioxidant; Volatile compounds; Sensorial acceptance; Functional food 